\title{
Uma análise exploratória do financiamento público à interação universidade-empresa no Brasil
}

\author{
Alex da Silva Alves ${ }^{\mathrm{a} *}$, José-Antônio Pimenta-Bueno ${ }^{\mathrm{b}}$ \\ a*alexds.alves@usp.br, Esalq/USP, Brasil \\ bjapb.br@gmail.com, PUC-Rio, Brasil
}

\begin{abstract}
Resumo
0 artigo explora o tema do financiamento do esforço de inovação das empresas por meio de parcerias com institutos de ciência e tecnologia, os quais, juntos, formam um importante indutor de políticas de fomento à inovação. No caso brasileiro, a combinação dos recursos de fomento federais e estaduais e a infraestrutura montada nas ICTs nas últimas décadas participam na consolidação desse esforço. 0 artigo traz reflexões sobre a interação universidade-empresa para a inovação a partir de uma survey realizada junto a ICTs e empresas participantes de um programa nacional de fomento entre 2002 e 2007, intitulado Coopera. Este artigo busca elucidar esses e outros aspectos da natureza da relação criada pelo Coopera. Embora se reconheçam os avanços alcançados, a análise sugere que o programa ainda não logrou estabelecer a qualidade e a periodicidade do relacionamento de que depende o esforço continuado de inovação no meio empresarial brasileiro.
\end{abstract}

Palavras-chave

Instituições de ciência e tecnologia. Política de ciência e tecnologia. Relação universidade-empresa.

\section{Introdução}

Nas últimas duas décadas, observa-se no Brasil um aumento expressivo das discussões na academia (MONTOBBIO; STERZ1, 2011; LA ROVERE; RODRIGUES, 2011) e no âmbito das políticas públicas (SCHWARTZMAN; BOTELHO; ALVES, 2009; CASSIOLATO; LASTRES, 2005) sobre os arranjos institucionais mais adequados para estimular a aproximação entre as universidades e centros de pesquisa (doravante ICTs) e o setor produtivo, forma de contribuir para a inclusão social, a geração de empregos qualificados e o aumento da competitividade das empresas. A interação de 1CTs com o setor produtivo, em particular o privado, tem sido o tema gerador de maiores discussões, dado o reconhecido papel exercido por cada um no desenvolvimento econômico (ETZKOWITZ et al., 2000; CARLSSON et al., 2007; DEWATRIPONT; STEIN, 2008).

A cooperação universidade-empresa assume estruturas organizacionais muito variadas - dependentes da maturidade da relação, dos objetivos da cooperação etc. -, mas toda essa variedade de meios resulta numa mesma finalidade: o desafio relevante intelectual para as universidades e a produção complementar de conhecimento para a empresa ao menor custo (GIULIANI et al., 2009).

0 presente trabalho tem por objetivo avaliar a eficácia de um programa estruturado de apoio à interação universidade-empresa, de âmbito nacional, cujo escopo era induzir a cooperação para a inovação, sobretudo nos casos em que esta era incipiente ou inexistente. Para tanto, foi realizada uma pesquisa do tipo survey junto a coordenadores de projetos submetidos e aprovados do programa Coopera, tanto do lado das ICTs quanto do das empresas.

0 trabalho divide-se em seis seções, incluindo esta introdução. A segunda seção revisa a literatura recente. A terceira apresenta o Coopera e seu contexto, em termos dos principais instrumentos do arcabouço de políticas de financiamento à ciência, à tecnologia e à inovação vigente no Brasil. A quarta dedica-se à apresentação do desenho da survey, incluindo a metodologia empregada e uma caracterização da amostra. A quinta mostra os principais resultados extraídos da survey e a sexta e última seção traz as conclusões do trabalho. 


\section{Interação universidade-empresa como estratégia de fomento à inovação tecnológica}

Em um estudo sobre as vantagens e desvantagens da pesquisa conjunta entre universidades e empresas, Aghion, Dewatripont e Stein (2008) mostram que a determinação de muitos cientistas em universidades de gozar de liberdade para trabalhar nos projetos que bem entenderem pode na realidade ser um bom incentivo para que as empresas busquem na universidade o conhecimento desejado para levar seus projetos a cabo, sobretudo aqueles em estágios iniciais de desenvolvimento. Os autores mostram que apesar dos incentivos financeiros concedidos a acadêmicos que se disponham a abrir mão de sua liberdade, realizar pesquisas mais embrionárias com universidades pode ser uma estratégia de alocação de recursos mais eficiente e eficaz.

Para potencializar os laços de cooperação entre pesquisadores de ICTs e empresas, muitos países estão introduzindo leis e fazendo inovações institucionais de diferentes tipos, ao mesmo tempo em que muitos grupos e institutos de pesquisa estão descobrindo seus próprios caminhos de vinculação e desenvolvimento de sua capacidade de inovação. As discussões envolvendo tais esforços não são recentes, como se nota em Webster (1994).

Até o momento, e com a ressalva de que muitas das iniciativas empreendidas ainda estão emergindo ou em andamento, as inovações políticas e institucionais almejadas no Brasil, embora com alguns resultados expressivos, sobretudo naqueles segmentos mais historicamente orientados à busca da inovação por meio da pesquisa científica como agroindústria e petróleo, tais esforços têm sido menos bem-sucedidos do que seria desejável (SCHWARTZMAN; BOTELHO; ALVES, 2009; MELO, 2009). Tal aspecto não afeta somente economias em desenvolvimento. Villa e Antonelli (2009) também apontam dificuldades similares em países europeus com elevada tradição em pesquisa científica.

No entanto, nos últimos anos, a despeito das barreiras institucionais e culturais (BOTELHO; ALMEIDA, 2010; MORELI, 2009; CRUZ; MELLO, 2006) que ainda persistem, há universidades e grupos acadêmicos de pesquisa brasileiros que conseguiram lograr avanços na sua colaboração com a indústria. Exemplos de experiências envolvendo esse esforço vêm sendo trazidos por estudos que discutem os resultados advindos de experiências recentes em longos projetos colaborativos entre universidades e empresas, tais como: i) a da Esalq-USP em um projeto trienal de cooperação com importantes empresas do setor agrícola e da Unicamp junto a uma multinacional da química fina (SCHWARTZMAN; BOTELHO; ALVES, 2009); ii) de diversas universidades brasileiras com a indústria farmacêutica (PARANHOS; HASENCLEVER, 2011); iii) da UFPE e Cesar com pequenas e médias empresas do setor de software em Recife (LA ROVERE; RODRIGUES, 2011); e da UFSC e a então Embraco, cujo relacionamento persiste há 20 anos, mesmo após a empresa ter sido adquirida pela americana Whirlpool (FINANCIADORA..., 2008). lgualmente, as universidades brasileiras vêm empreendendo esforços no sentido de buscar a melhoria da qualidade dos serviços prestados às empresas, como reportado por Matei et al. (2012) em trabalho realizado junto à UFRGS.

Em geral, em que pesem as virtudes das interações mais espontâneas e seu impacto no desenvolvimento das instituições e empresas envolvidas, o ritmo das interações não alcança o que se percebe como suficiente para cumprir com o papel almejado para sua contribuição ao desenvolvimento socioeconômico de regiões ou países (WEBSTER, 1994; SAPIR et al., 2003). Daí a justificativa às interações induzidas por meio de estímulos governamentais, que ajudariam a superar as barreiras percebidas da relação (TASSEY, 1997). Resumidamente, sob a óptica da política pública, o que se espera é que a convivência inicialmente induzida por mecanismos de fomento resulte, futuramente, em maior convivência espontânea (ANTONELLl, 2001).

No âmbito da promoção dessas interações induzidas, o governo brasileiro, por meio da Finep, promoveu um conjunto de ações estruturadas, denominadas programa Coopera. A pedido da Finep, os autores realizaram um estudo junto aos participantes do referido programa, ao nível de projeto de cooperação. 0 referido trabalho é parte de um esforço maior, que dá sequência a estudos promovidos pelo Centro de Gestão e Estudos Estratégicos - CGEE, sob encomenda da Finep, a respeito do uso de instrumentos de fomento à inovação no meio empresarial. No presente estudo, conduzido por meio de uma pesquisa do tipo survey, avaliou-se um conjunto de 87 instrumentos desenvolvidos no âmbito do programa Coopera. 0 programa, que tem seu marco legal anterior à Lei da Inovação de 2004, foi implementado através de um conjunto variado de editais, cartas-convite e encomendas no período de 2002 a 2007, através dos quais o apoio financeiro às empresas fluía por meio das ICTs e, portanto, era indireto. Embora ainda ativo, o Coopera perdeu força, pois a Lei da Inovação permitiu criar outros instrumentos de apoio direto às empresas, como é o caso do programa de Subvenção Econômica à Inovação (SEI).

\section{0 programa Coopera em seu contexto}

A partir da segunda metade da década de 90, após uma década de estagnação econômica no 
país, a questão da promoção do desenvolvimento científico e tecnológico foi retomada, com foco maior na necessidade de aumentar a capacidade competitiva da indústria nacional em um contexto de maior abertura da economia, fazendo uso, para isso, da competência científica e técnica que estava se desenvolvendo nas universidades de ponta. Desde então, vários avanços institucionais foram verificados, dentre os quais sobressaem-se, por sua amplitude, os fundos setoriais, a Lei da Inovação, a Lei do Bem e o Plano de Desenvolvimento Produtivo e, mais recentemente, o Plano Brasil Maior. O presente trabalho não irá adentrar na descrição e análise dessas iniciativas, uma vez que há uma gama substancial de estudos a respeito (NOGUEIRA; KUBOTA; MILANI, 2011; BRITTO et al., 2010; VERMULUM; HOLLANDA, 2008; CASSIOLATO; LASTRES, 2005). 0 que se fará nesta seção será um esforço de enquadrar o programa dentro do contexto vigente à sua época, o que implica uma conceituação do programa assim como da sua visão sob a óptica de seus idealizadores.

\subsection{O programa segundo seus idealizadores}

Como primeiro passo do processo de apreciação do programa Coopera, esta seção dedica-se à apresentação da visão que, se acredita, orientou sua implementação e, por conseguinte, os resultados alcançados. No curso da busca dessa visão, feita sobre documentos públicos disponíveis na internet, constatou-se uma pequena, mas importante, variedade de visões.

No relatório de atividades da agência do ano 2004 (FINANCIADORA..., 2004), o Coopera é descrito como um instrumento cuja finalidade é apoiar projetos de pesquisa, desenvolvimento e inovação tecnológica de interesse de empresas brasileiras a serem executados em parceria com 1CTs. Nessa descrição surge uma qualificação importante: o apoio é para projetos de interesse das empresas e esta não pode ter um significado superficial, já que, num contexto de cooperação, há que haver o interesse de ambas as partes. Assim, a qualificação deve possuir um significado mais profundo para justificar sua menção.

Em apresentação realizada no Fórum de Pró-Reitores de Pesquisa da Região Sudeste, em 2007 (COELHO, 2007), acrescenta-se uma nova qualificação ao fomento da cooperação: quando se trata das pequenas e microempresas, o apoio destina-se aos esforços de cooperação no contexto de Arranjos Produtivos Locais (APLs). Assim, o programa, nesse segmento, sofre uma mudança de rumo e as ações de fomento são destinadas ao desenvolvimento de APLs, que passam a fazer parte dos instrumentos de apoio à cooperação.
A noção do Coopera, como abrangendo outras iniciativas relacionadas à interação ICT X Empresas, foi primeiro observada no Relatório de Gestão da Finep para o período 2003-2006 (FINANCIADORA..., 2006). Há dois destaques importantes nessa visão: primeiro, a noção de que o Coopera possui subprogramas; segundo, a noção de que, enquanto o outro programa, a Subvenção Econômica à lnovação (SEI), é o instrumento que direciona apoio diretamente às empresas, sem a necessidade de uma figura executora adicional, o Coopera deve ser o instrumento de apoio (subvenção) indireto às empresas. Essa visão do Coopera configura as ICTs em veículos legais de apoio público às empresas, contornando o marco legal da época que ainda não autorizava a subvenção direta às empresas - o que só veio a ocorrer, na prática, em 2006, com o primeiro edital da SEl, amparado pela Lei da Inovação. Tanto o Coopera quanto o SEI contam com recursos provenientes dos fundos setoriais.

Dentre essas interpretações, entende-se que o significado pretendido pela agência é de que o programa Coopera se voltaria para o atendimento da demanda tecnológica das empresas, e não para o aproveitamento de oportunidades comerciais surgidas do lado ofertante (i.e., inovações derivadas da pesquisa das ICTs).

Na apresentação da Finep no XX Fórum Nacional de Ciência e Tecnologia, em 2008, o Coopera é apresentado como instrumento de fomento a projetos de PD\&1 de interesse de empresas, cujas atividades sejam realizadas em 1CTs brasileiras, garantindo 0 custeio das atividades nas ICTs e, ainda, o reforço a sua infraestrutura de pesquisa (FERNANDES, 2008). Essa visão do Coopera, manifestada pela presidência da Finep em 2008, reforça a visão de 2004 e sublinha o papel das ICTs como, fundamentalmente, prestadoras de serviços - uma vez que as atividades apoiadas seriam realizadas nas ICTs, que se beneficiariam com acréscimos na sua infraestrutura.

Há, pois, duas visões pragmáticas a respeito do papel das ICTs nas relações com o meio empresarial no contexto da inovação: uma de prestadora de serviços avançados, que faz uso de infraestruturas especializadas e caras que se renovam pelo acesso privilegiado a recursos públicos (AGHION; DEWATRIPONT; STEIN, 2008; CARLSSON et al., 2007); outra de fonte de novos conhecimentos potencialmente úteis, que depende das empresas para produzir retorno tangivel para a sociedade - i.e., de empresas como veículos da inovação (MONTOBBI0; STERZl, 2011; ETZKOWITZ et al., 2000).

Cada visão dessas enseja uma correspondente interpretação sobre o papel das ICTs no processo de inovação: assim, no papel de prestadoras de serviços, as ICTs são convocadas a preencher uma eventual 
lacuna na base de conhecimentos da empresa (ou outro recurso especializado) pertinente a uma inovação em curso. Já no outro papel a ICT é a base dos ativos intelectuais que nortearão o desenvolvimento de novos negócios abrigados numa empresa existente ou numa nova, especialmente criada para tal propósito. Esses dois papéis se desenvolvem em regimes jurídicos distintos: o primeiro, de contrato de prestação de serviços, e o segundo, de contrato de licenciamento (ou venda) de propriedade intelectual.

Claramente, esses dois papéis das ICTs não são substitutos, mas complementares. lsto é, o exercício de um não sobrevive sem o exercício do outro papel, o que acontece por razões diversas, inclusive de ordem cultural (BOTELHO; ALMEIDA, 2010). Entretanto, o Coopera alinhou-se tão somente ao primeiro dos papéis, talvez contando com a existência de outros programas que viriam a desenvolver o segundo, como o próprio SEl.

A falta de maior coerência na visão oficial do papel das ICTs na inovação se explica, em parte, pela novidade desse exercício intelectual específico, pela complexidade deste e, ainda, por diferenças pessoais no entendimento da natureza e do objeto do fomento governamental à inovação. De fato, a atividade de inovação é afetada por sérias deficiências conceituais - como a frequente confusão que se faz entre inovação e invenção - que culminam no entendimento de que o apoio à inovação se faz através do apoio à P\&D (TASSEY, 1997). Com esse entendimento, a estratégia histórica do apoio à $\mathrm{P} \& \mathrm{D}$ pode ser interpretada como apoio à inovação, podendo culminar em resultados aquém dos desejados por seus idealizadores (SAPIR et al., 2003).

\subsection{Marco conceitual do programa}

Esse item elabora um marco conceitual do Coopera que organiza e, assim, ajuda a compreender a gama de instrumentos e ações de fomento que foi reunida sob essa denominação. 0 conceito basilar, que unifica esses instrumentos e ações de fomento, é a importância, para as iniciativas de inovação, da presença da cultura da cooperação, conforme já salientado.

logo, a existência de uma ação de fomento estruturante, voltada para promoção e exploração da cultura de colaboração para inovação, é legítima e justificada. Tal ação estruturante promoveria a colaboração tanto na execução de projetos de inovação como, também, no fomento à inovação - algo que o Coopera realizou. De fato, vários de seus instrumentos envolveram uma ação de fomento combinada, reunindo, de um lado, a Finep e, de outro, entidades com demandas tecnológicas orientadas a fins específicos (finalísticas), como a Petrobras, Eletrobrás, Fundação Nacional de Saúde e a Caixa Econômica Federal; nas demais, o fomento foi promovido somente pela Finep. Tal arranjo é visto na Figura 1.

$\mathrm{Na}$ execução, o fomento à cooperação se deu em três frentes: primeiro, no requerimento da cooperação para alcançar determinados objetivos finalísticos (e.g., um determinado equipamento para a Petrobras); na segunda, nos temas de natureza livre; e, por último, nos projetos voltados ao fortalecimento da "infraestrutura" da cooperação ICT $\times$ empresa, incluindo: a modernização dos laboratórios das ICTs que atendem demandas das empresas, o apoio a ambientes de cooperação, como incubadoras e parques tecnológicos, o apoio a estruturas de intermediação (como os núcleos de inovação tecnológica - NITs) e, ainda, as ações voltadas para TIB - tecnologia industrial básica. Esses elementos completam a estrutura de fomento apresentada na Figura 1.

A partir dos dados da Tabela 1 é possível apreciar que a ação de fomento finalística, onde a

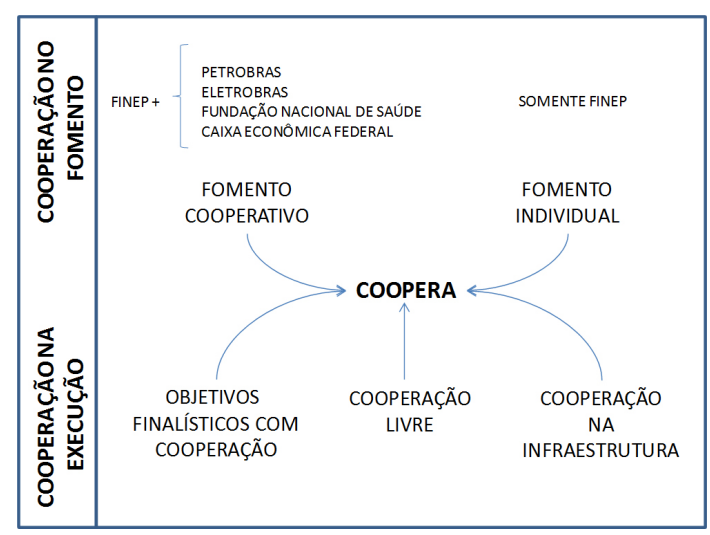

Figura 1. Caracterização do fomento no âmbito do programa Coopera. Fonte: elaboração própria.

Tabela 1. Perfil dos instrumentos de cooperação no programa Coopera.

\begin{tabular}{lcccc}
\hline & Finalísticos com cooperação & Cooperação livre & Infraestrutura de cooperação & Total \\
\hline Número de instrumentos & 35 & 16 & 11 & 62 \\
Valor dos instrumentos (R\$ MM) & 293,60 & 268,00 & 157,30 & 721,90 \\
Número de propostas submetidas & 1.706 & 1.433 & 1.378 & 4.517 \\
Valor das propostas (R\$ MM) & 762,00 & 631,50 & 656,10 & $2.049,60$ \\
\hline
\end{tabular}

Fonte: elaboração própria. 
cooperação aparece como um meio para alcançar um fim tecnológico específico, foi a mais estimulada pela agência - em número de instrumentos e no valor alocado - e a mais demandada (em termos absolutos) - tanto em número quanto em valor das propostas. A intensidade da demanda, por sua vez, foi mais elevada na modalidade de infraestrutura - foram demandados 4,2 mais recursos do que o alocado. Nas demais modalidades o múltiplo foi de 2,6 (finalístico) e 2,3 (cooperação livre).

Claramente, o principal fomento cooperativo se dá por meio dos projetos cooperativos finalísticos que se dirigem para demandas específicas do parceiro tecnológico da agência, como, por exemplo, a substituição de determinada importação. Tais projetos assumem, tipicamente, duas configurações, conforme esquemas apresentados na Figura 2.

$\mathrm{Na}$ configuração da esquerda, o parceiro tecnológico da agência (exemplificada pela Petrobras) é, simultaneamente, o demandante (da tecnologia) e o proponente do projeto que atenderá a essa demanda; nesse caso, a ICT coopera, diretamente, com o demandante. Na configuração da direita, aparece a figura do "fornecedor" que se propõe a atender a demanda expressa pelo parceiro tecnológico num esforço cooperativo com a ICT e orientada pelo parceiro.

0 fomento cooperativo finalístico, que reúne a Finep com um parceiro tecnológico, é motivado pela atratividade econômica da demanda tecnológica - e.g., das oportunidades de substituição de importações para potenciais fornecedores nacionais e pela capacitação técnica requerida na especificação da demanda, na seleção das propostas e na capacidade de gestão do parceiro tecnológico no acompanhamento e na aceitação final dos resultados do projeto cooperativo.
Assim, em troca da prerrogativa de direcionar o fomento para o atendimento dessa demanda, o parceiro tecnológico é motivado a aportar recursos financeiros e gerenciais complementares aos disponibilizados pela Finep.

No desenho da política nacional de PD\&l brasileiro existe uma clara preferência pelo fomento através de agências genéricas (multipropósitos, missões difusas e não especializadas) - cujos "radares" de prospecção cobrem todas as áreas do conhecimento ou todos os segmentos industriais -, e, por conta disso, não são elas as usuárias dos resultados técnicos produzidos. Não raro, por não terem um foco finalístico, essas agências terminam por se especializarem nos instrumentos de fomento - i.e., nos meios. Com isso, essas agências travam dificuldades em desenvolver sua reputação junto às comunidades científicas e tecnológicas nas quais investem (BOTELHO; PIMENTA-BUENO, 2009).

Para superar essa dificuldade, o caminho seguido pelas agências foi o de formação de parcerias com entidades - sobretudo públicas - de reconhecida liderança em suas áreas, as quais, por sua vez, poderiam vir a tornarem-se usuárias dos resultados produzidos. Isso ocorreu no âmbito do Coopera, na junção da Finep com empresas públicas de amplitude nacional para formação de chamadas públicas com propósitos finalísticos. Essas entidades parceiras trouxeram um conjunto de vantagens ao fomento: primeiro, contribuíram na especificação da demanda; segundo, na seleção técnica das propostas; terceiro, na disponibilização de recursos financeiros adicionais; quarto, no acompanhamento das propostas e, quinto, na possibilidade de virem a se tornar clientes do produto final produzido. Essa última contribuição pode reduzir o risco moral a que a agência estaria exposta na ausência do parceiro. No entanto, o apoio

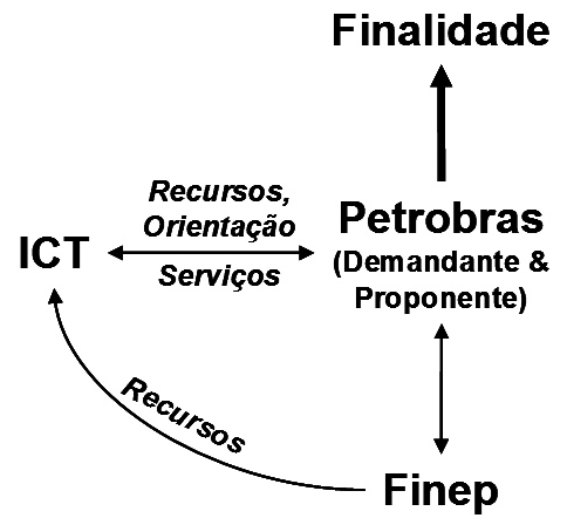

Cooperação Direta com Demandante

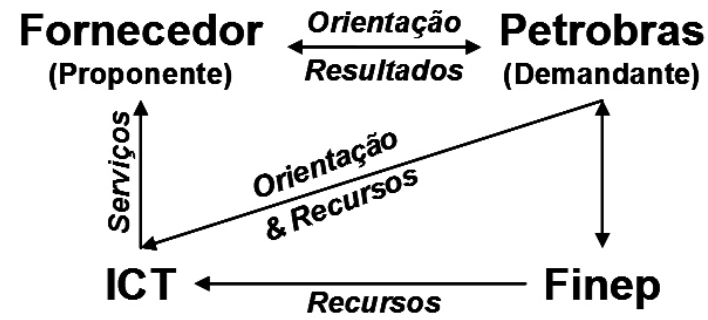

Cooperação Indireta com Demandante

Figura 2. Exemplificação do fomento finalístico. Fonte: elaboração própria. 
não reembolsável a esses projetos, de no máximo $R \$$ 250 mil por projeto, não pareceu ser suficiente para garantir o atendimento aos objetivos delimitados em muitas das cartas-convite e editais envolvendo essas parcerias conjuntas, como, por exemplo, os objetivos de: "propiciar significativa agregação de valor", "trazer relevantes contribuições para o desenvolvimento sustentável", em especial na "balança comercial", e "fortalecer diversas cadeias produtivas, com relevantes impactos para o desenvolvimento regional”.

\section{A survey: desenho, metodologia e amostra}

Descreve-se aqui o instrumento utilizado para levantar a percepção dos usuários do Coopera se de fato o referido programa contribuiu para atingir seus objetivos de promover e qualificar a interação ICT $\times$ empresa para inovação. São apresentados o desenho e a metodologia da pesquisa tipo survey e, ainda, a caracterização da amostra, constituída por coordenadores dos projetos cooperativos tanto do lado das ICTs executoras quanto das empresas intervenientes.

\subsection{O desenho da survey}

Os questionários contaram com duas versões, sendo uma para as empresas e a outra para as ICTs. As perguntas foram organizadas segundo as principais questões de interesse, de modo a orientar as respostas para as perguntas que deram origem a este trabalho de pesquisa, como também para subsidiar avaliações futuras. A Tabela 2 apresenta os aspectos da survey, os quais delinearam as perguntas dos questionários.

0 questionário, eletrônico, foi estruturado de modo a incorporar questões que permitam a construção de indicadores quantitativos e qualitativos com vistas a contemplar, dentre outros aspectos: a produção técnico-científica; a formação e capacitação de recursos humanos; a natureza e alcance das colaborações formalizadas; os processos de absorção, transferência e comercialização de tecnologias, dentre outros.

Tabela 2. Aspectos delineadores da survey.

\begin{tabular}{lcc}
\multicolumn{1}{c}{$\begin{array}{c}\text { Questões de } \\
\text { interesse }\end{array}$} & Dimensões & $\begin{array}{c}\text { Número de } \\
\text { questões }\end{array}$ \\
\hline $\begin{array}{l}\text { Aspectos da } \\
\text { cooperação }\end{array}$ & - & 9 \\
$\begin{array}{l}\text { Instrumentos de } \\
\text { apoio }\end{array}$ & $\begin{array}{l}\text { Marco legal, transferência de } \\
\text { conhecimento/tecnologia, } \\
\text { aspectos e histórico da parceria }\end{array}$ & 9 \\
$\begin{array}{l}\text { Motivação da } \\
\text { cooperação }\end{array}$ & - & 1 \\
\hline Fonte: elaboração própria.
\end{tabular}

Fonte: elaboração própria.

\subsection{Aspectos metodológicos da pesquisa}

A survey se deu por meio da aplicação de questionários estruturados utilizando uma ferramenta para pesquisas de opinião utilizada pelo CGEE. 0 link de acesso para o questionário eletrônico foi enviado ao endereço eletrônico dos participantes dos projetos aprovados nas empresas e nas ICTs, os quais tiveram 45 dias para responder. A avaliação ocorreu entre os meses de agosto e setembro de 2009.

0 trabalho de pesquisa caracteriza-se como exploratório, dado que, a partir das informações extraídas das ICTs e empresas participantes do Coopera por meio da survey, acreditou-se ser possível alcançar alguma conclusão a respeito da problemática estudada.

Como se verá diante, a amostra, apesar de representar parcela significativa da população usuária do programa, não é representativa da população de usuários de recursos de fomento público à inovação. Tal aspecto é inerente a pesquisas exploratórias (MIGUEL, 2012), as quais normalmente são realizadas sobre uma amostra não representativa do universo da população (todas empresas usuárias de recursos públicos de fomento).

\subsection{Caracterização da amostra}

As empresas que participaram desta pesquisa foram de médio e grande porte. Conforme o conjunto de editais, chamadas públicas e cartas-convite que caracterizam o programa no período avaliado, entre 2002 e 2007, os projetos objeto de fomento deveriam ser de inovação - i.e., propor ao mercado um produto, serviço ou processo novo ou aperfeiçoado - e não de pesquisa, i.e., e os projetos deveriam gerar conhecimento novo e de valor econômico.

0 questionário eletrônico foi aplicado a um grupo de 546 responsáveis das 468 empresas cujos projetos foram realizados no âmbito do programa, assim como a 175 responsáveis pelos mesmos projetos em 149 ICTs. Um grupo de 63 respondentes de 49 empresas retornou os questionários preenchidos, perfazendo um total de $10 \%$ de respondentes das empresas. Nas ICTs, houve 131 respondentes de 79 ICTs, perfazendo uma taxa de resposta de 53\%. As 79 ICTs representadas na amostra submeteram 562 projetos aprovados entre 2002 e 2007, dos quais 70\% foram submetidos por somente 14 das 79 ICTs. Cada respondente equivale a um projeto submetido e aprovado.

0 perfil da amostra referente às empresas consultadas reflete a elevada concentração que se observa no universo de participantes do programa. Conforme se observa na Tabela 3, somente a empresa Petrobras S.A. - incluindo seu centro de pesquisas, o Cenpes - submeteu mais de $80 \%$ do total de projetos de todos os 63 respondentes das 49 empresas que 
retornaram os questionários. Apenas 5 empresas foram responsáveis por $92 \%$ do total de projetos submetidos pelas empresas respondentes.

Visando entender o nível de concentração das propostas, tanto em relação às empresas quanto às ICTs, foram selecionadas as empresas com 5 ou mais interações e as ICTs com 10 ou mais interações no período analisado. Segundo esse critério, as empresas que mais participaram das interações estão listadas na Tabela 4, enquanto as 1CTs são listadas na Tabela 5.

Conforme se observa na Tabela 4, a interação é fortemente concentrada em ambos os lados. As 12 empresas com 5 ou mais interações no período de 2002 a 2007 responderam por 38\% do total das empresas que participaram do programa; dentre essas 12, apenas 1 - a Petrobras - responde por mais da metade das interações do grupo. No caso da amostra, apesar de o percentual de empresas das amostras com 5 ou mais interações ser superior ao do total de empresas envolvidas no programa (51\% contra 38\%), a Petrobras também figura como responsável por metade das interações da amostra. Conforme a Tabela 5, as 14 ICTs com 10 ou mais interações responderam por 55\% das 1CTs que participaram do programa.
Conforme a Figura 3, que apresenta os projetos segundo seu porte, é a forte concentração de empresas (35 empresas ou 73\% do total) e ICTs (49 ICTs ou $65 \%$ do total) em projetos entre R\$ 100 mil e $\mathrm{R} \$ 1$ milhão, mais particularmente na faixa entre $\mathrm{R} \$ 100$ e R\$ 500 mil onde se concentram nada menos que 38\% das empresas e 37\% das ICTs consultadas.

A elevada concentração de projetos de pequeno valor (até R\$ 1 milhão) observada na Figura 3 é consistente com uma observação a ser feita adiante, a da também elevada concentração de projetos buscando vencer os estágios iniciais do processo de inovação.

\section{Análise dos resultados da survey}

Nesta seção, apresentam-se os principais resultados observados a partir da survey realizada junto a ICTs e empresas de médio e grande porte que participaram do programa. No período em análise, de 2002 a 2007, 1.184 projetos submetidos foram aprovados (contra 4.517 projetos demandados) com recursos da ordem de $\mathrm{R} \$ 473$ milhões (contra $\mathrm{R} \$ 2$ bilhões demandados).

Tabela 3. Projetos aprovados (total e amostra - 2002-2007).

\begin{tabular}{|c|c|c|c|c|c|c|c|c|}
\hline Empresas & 2002 & 2003 & 2004 & 2005 & 2006 & 2007 & Total & Amostra \\
\hline Petróleo Brasileiro S.A & 14 & 88 & 106 & 116 & 140 & 8 & 472 & 21 \\
\hline Whirlpool S.A - Unidade Embraco & 5 & 0 & 4 & 1 & 9 & 0 & 19 & 5 \\
\hline Braskem S.A & 0 & 2 & 0 & 0 & 7 & 0 & 9 & 5 \\
\hline Embraer - Empresa Brasileira de Aeronáutica S.A & 1 & 1 & 0 & 2 & 3 & 1 & 8 & 5 \\
\hline Companhia Siderúrgica Nacional - CSN & 5 & 0 & 0 & 0 & 0 & 0 & 5 & 3 \\
\hline Demais empresas $(n=44)$ & 20 & 6 & 12 & 9 & 8 & 0 & 55 & 24 \\
\hline Total - primeiras 5 empresas & 25 & 91 & 110 & 119 & 159 & 9 & 513 & 58 \\
\hline Total - todas as empresas & 45 & 97 & 122 & 128 & 167 & 9 & 568 & 63 \\
\hline Participação das primeiras 5 empresas no total de projetos & $56 \%$ & $94 \%$ & $90 \%$ & $93 \%$ & $95 \%$ & $100 \%$ & $90 \%$ & $92 \%$ \\
\hline
\end{tabular}

Fonte: elaboração própria.

Tabela 4. Empresas com maior interação.

\begin{tabular}{|c|c|c|c|c|c|}
\hline \multicolumn{2}{|r|}{ Empresas parceiras } & \multirow{2}{*}{$\begin{array}{c}\text { Total } \\
236\end{array}$} & \multirow{2}{*}{$\frac{\text { Amostra }}{19}$} & \multirow{2}{*}{$\frac{\% \text { Total }}{26}$} & \multirow{2}{*}{$\frac{\% \text { Amostra }}{30}$} \\
\hline 1 & Petróleo Brasileiro S.A. & & & & \\
\hline 2 & Whirpool S.A. - Unid. Embraco & 19 & 4 & 2 & 6 \\
\hline 3 & Centrais Elétricas Brasileiras S.A. & 19 & 1 & 2 & 2 \\
\hline 4 & Oxiteno S.A. Indústria e Comércio & 13 & 1 & 1 & 2 \\
\hline 5 & Braskem S.A. & 9 & 2 & 1 & 3 \\
\hline 6 & Embraer - Empresa Brasileira de Aereonáutica S.A. & 8 & 2 & 1 & 3 \\
\hline 7 & Cia. Siderúrgica de Tubarão & 8 & 2 & 1 & 3 \\
\hline 8 & Biosintética Farmacêutica Ltda. & 8 & 1 & 1 & 2 \\
\hline 9 & Politeno Ind. Com. Ltda. & 6 & 1 & 1 & 2 \\
\hline 10 & Natura Inovação e Tecnologia de Produtos Ltda. & 6 & 2 & 1 & 3 \\
\hline 11 & Operador Nacional do Sistema Elétrico & 5 & 1 & 1 & 2 \\
\hline \multirow[t]{3}{*}{12} & Cia Siderúrgica de Tubarão & 5 & 1 & 1 & 2 \\
\hline & Demais & 554 & 26 & 62 & 41 \\
\hline & Total & 896 & 63 & 100 & 100 \\
\hline
\end{tabular}

Fonte: elaboração própria. 


\subsection{Sobre os resultados mais significativos da parceria}

A Figura 4 e a Figura 5 trazem as perspectivas das empresas e das ICTs sobre quais os resultados alcançados que julgaram mais significativos.

De maneira geral, o programa atendeu mais os objetivos-fim das ICTs do que os das empresas e mais aos objetivos-meio das empresas do que das ICTs, conforme se observa na Tabela 6. Esse resultado não é surpreendente, já que na maioria das empresas os resultados de um projeto de P\&D estão mais distantes dos seus objetivos finais do que para os objetivos finais das ICTs. Como se vê na Tabela 6,

Tabela 5. ICTs com maior interação.

\begin{tabular}{llcccc}
\hline \multicolumn{1}{c}{ ICTs } & Total & Amostra & \%Total & \%Amostra \\
\hline 1 & UFRJ & 77 & 6 & 10 & 7 \\
2 & UFSC & 72 & 9 & 10 & 11 \\
3 & UFRGS & 43 & 6 & 6 & 7 \\
4 & USP & 34 & 5 & 5 & 6 \\
5 & PUC-Rio & 30 & 2 & 4 & 3 \\
6 & UFBA & 24 & 3 & 3 & 4 \\
7 & Unicamp & 24 & 1 & 3 & 1 \\
8 & UFCE & 19 & 1 & 3 & 1 \\
9 & UGRN & 17 & - & 2 & 0 \\
10 & IPT-SP & 17 & 2 & 2 & 3 \\
11 & UFMG & 13 & - & 2 & 0 \\
12 & UFES & 12 & - & 2 & 0 \\
13 & CESAR-Recife & 11 & 1 & 1 & 1 \\
14 & UFPE & 11 & 2 & 1 & 3 \\
& Demais (N = 135) & 337 & 42 & 45 & 53 \\
& Total & 741 & 79 & 100 & 100 \\
\hline
\end{tabular}

Fonte: elaboração própria. por volta de $25 \%$ dos respondentes empresariais apontaram ao menos um dos objetivos finalísticos como estando entre os resultados mais marcantes. Entre os respondentes das ICTs o percentual parece superior, particularmente com respeito aos resultados relacionados à produção de conhecimento, que variou entre $25 \%$ a $60 \%$, dependendo da natureza e do grau de novidade do conhecimento em questão. Com relação aos objetivos-meio, o percentual de empresas que os destacaram como mais marcantes foi quase 0 dobro do percentual das ICTs. Cabe reconhecer que esses objetivos-meio, de uma e da outra parte, são, na verdade, os objetivos-fim do programa - estímulo à cooperação na inovação; assim, aos olhos das empresas consultadas, o Coopera foi mais eficaz do que aos olhos das ICTs.

Embora não sejam perfeitamente alinhados, não parece haver um descolamento entre as percepções dos resultados da parceria para as empresas e para as ICTs. Enquanto as primeiras apontam que a parceria potencializou novos projetos e contribuiu para melhorar a qualidade dos seus produtos e serviços, as ICTs vão além e afirmam que a parceria potencializou a geração de conhecimento técnico e científico novo para ambos. Tanto empresas quanto ICTs afirmaram que houve pouco aproveitamento de pesquisadores (mestres e doutores) nas empresas após a conclusão dos projetos.

Segundo os consultados, a parceria pouco contribuiu para a consolidação dos laços necessários à formação de redes de cooperação para P,D\&l, o que indica que praticamente não houve formação de capital social entre os participantes em decorrência da interação.

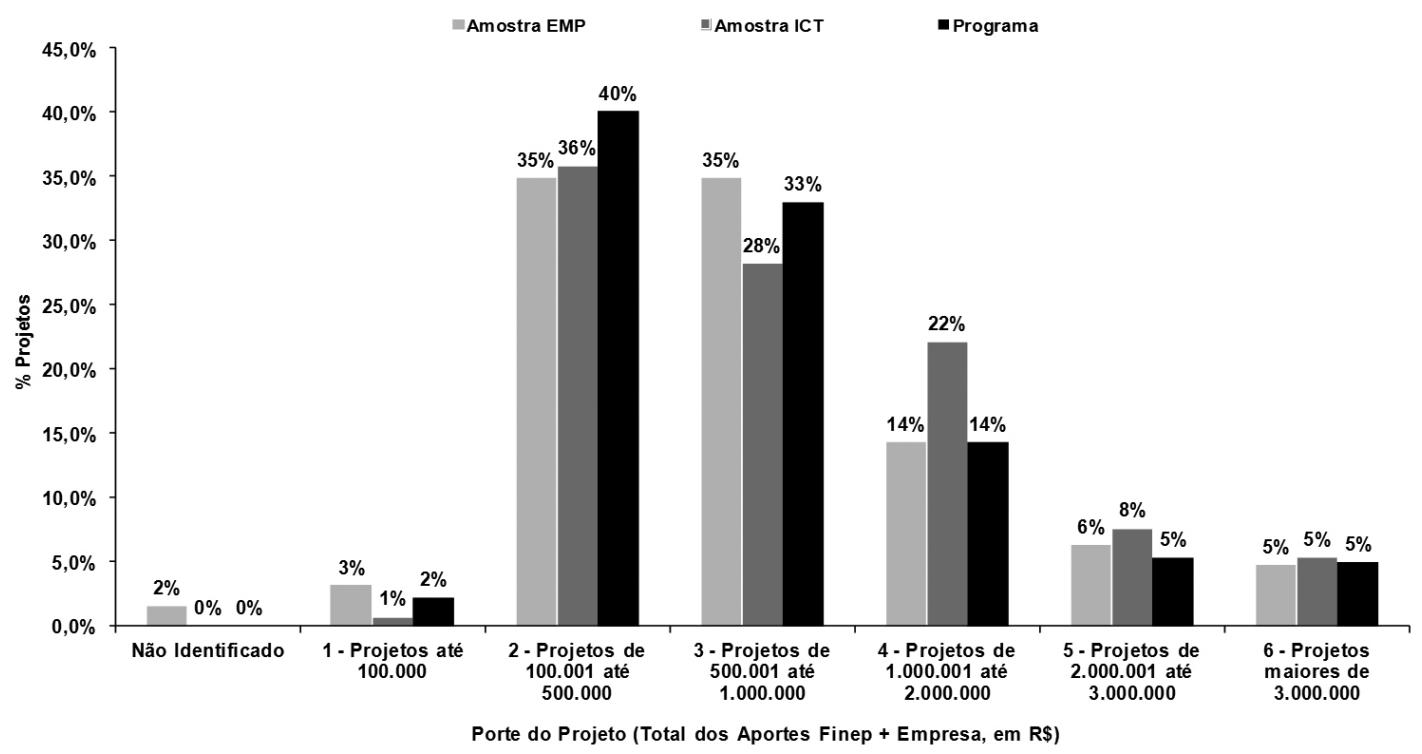

Figura 3. Porte dos projetos aprovados. Fonte: elaboração própria a partir dos dados da survey. 


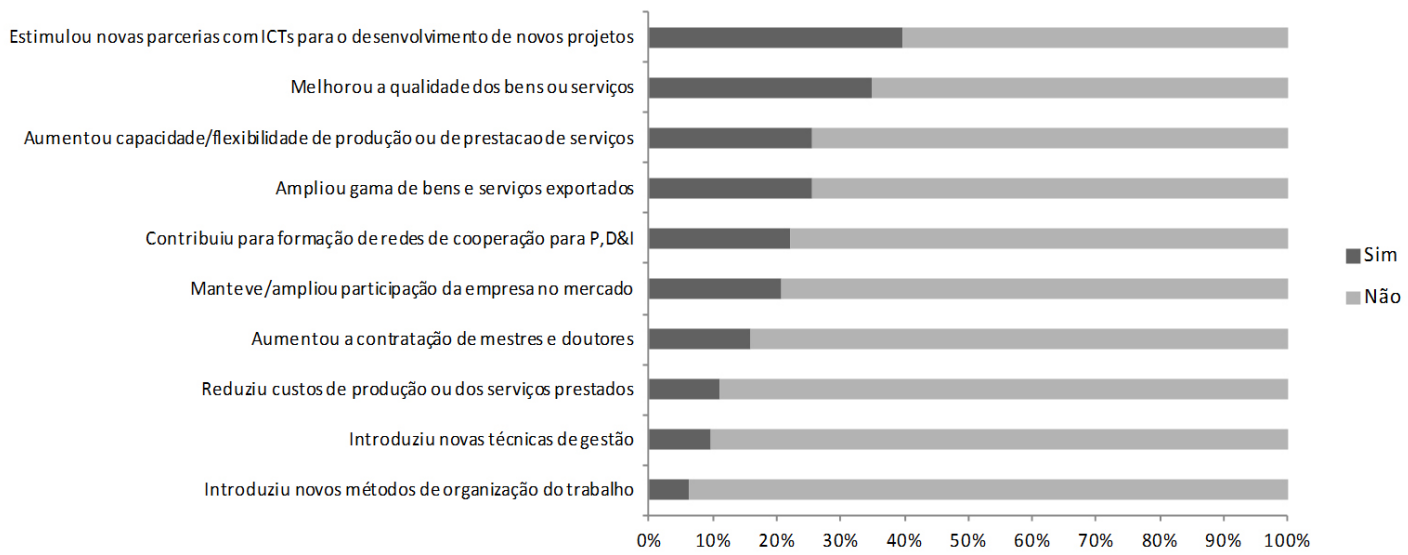

Figura 4. Itens mais representativos da parceria (empresas).

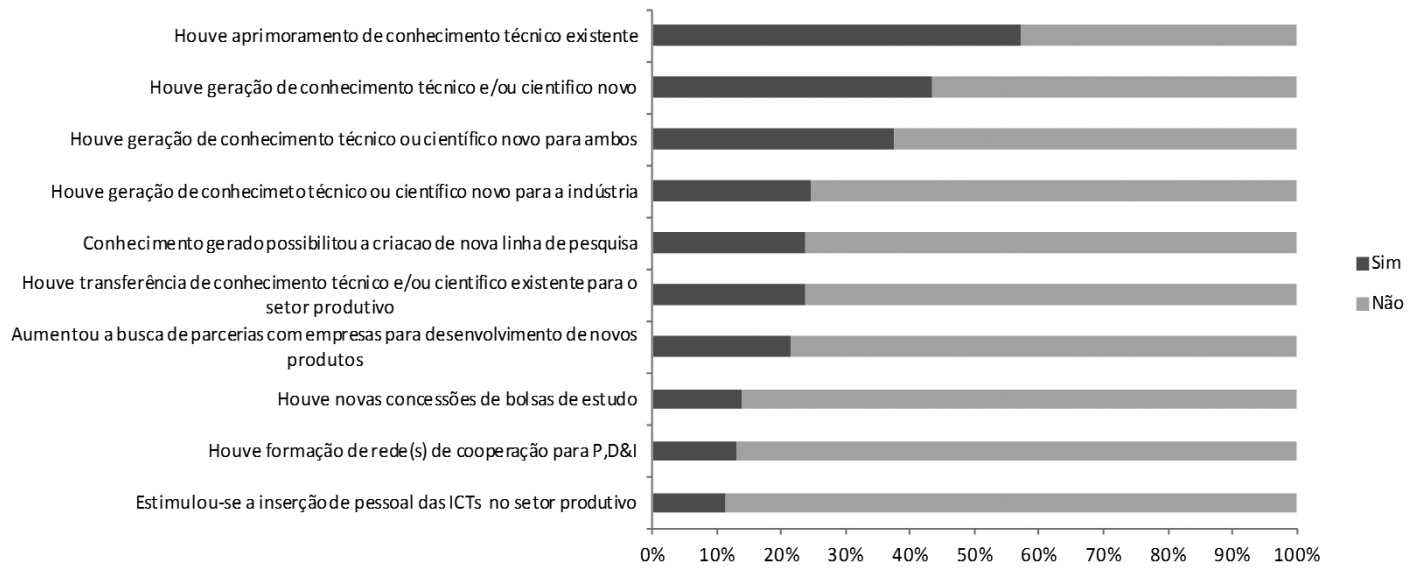

Figura 5. Itens mais representativos da parceria (1CTs). Fonte: elaboração própria.

Tabela 6. Caracterização dos resultados obtidos, segundo os respondentes.

\begin{tabular}{llc}
\hline \multirow{2}{*}{ Objetivos } & \multicolumn{2}{c}{ Respondentes } \\
\cline { 2 - 3 } & Empresas & ICTs \\
\hline Objetivos finalísticos & & \\
Empresas & & \\
Elevar qualidade do produto & $32 \%$ & \\
Ampliar capacidade de produção & $25 \%$ & \\
Ampliar exportação & $25 \%$ & \\
Elevar participação no mercado & $20 \%$ & \\
Reduzir custos & $10 \%$ & \\
& & \\
ICTs & & $25 \%$ a $60 \%$ \\
$\quad$ Produção de conhecimento novo & & $25 \%$ \\
Novas linhas de pesquisa & & $25 \%$ \\
Transferência de conhecimento & & \\
Objetivos-meio & & $12 \%$ \\
Estimular novas parcerias & $40 \%$ & $12 \%$ \\
Formar novas redes cooperativas & $22 \%$ & \\
Transferência/Absorção de RH & $15 \%$ & \\
\hline
\end{tabular}

Fonte: elaboração própria.

\subsection{Sobre as motivações para a cooperação}

Esse item enfoca os motivos que levaram empresas e ICTs participantes do Coopera a juntarem-se em esforços cooperativos para a inovação. A Tabela 7 apresenta os resultados da consulta.

A principal motivação para ambas as partes envolvidas é o acesso aos recursos públicos de fomento; a maioria das empresas e ICTs reportaram essa motivação. Isso se confirma ao se retirar os respondentes da Petrobras da amostra de empresas, fato que inclusive aumenta a incidência de respondentes que enfatizam o aspecto financeiro da motivação ao cooperar.

Os resultados da Tabela 7 não surpreendem, haja vista o estágio da inovação tecnológica no país (CRUZ; MELLO, 2006), além de fatores como os altos custos incorridos no processo produtivo das empresas e a necessidade das universidades de captar recursos 
fora do financiamento governamental (BOTELHO; ALMEIDA, 2010; MELO, 2009).

É interessante observar, ainda, que as ordenações das motivações são praticamente idênticas e revelam, ainda, que fatores relacionados à proximidade interpessoal e física tiveram pouca influência para os respondentes.

\subsection{Sobre o estágio de desenvolvimento da oportunidade no momento da cooperação}

Esse item busca verificar se as parcerias promovidas pelo Coopera se desenvolvem mais em determinados estágios de desenvolvimento da oportunidade de inovação do que em outros. A Figura 6 apresenta os resultados.
A análise dessa questão requer algumas considerações: em primeiro lugar, a possivel divergência de opinião entre as partes quanto à classificação do estágio da oportunidade no momento da formação da parceria. Outro fator que influencia a análise é que as respostas não foram "casadas" - i.e., o universo de propostas reportadas pelas empresas não é o mesmo das reportadas pelas 1CTs. Finalmente, a proporção de ICTs participantes da consulta foi maior que a de empresas, o que tende a elevar a presença das propostas nos estágios de maior interesse das ICTs.

Em que pese ser um programa de apoio à inovação, que em última análise se manifesta pela inserção de algo novo no mercado, nenhum dos participantes da consulta mencionou haver participado de cooperação em fase de comercialização pioneira, embora $2 \%$ das

Tabela 7. Motivações para a cooperação.

\begin{tabular}{|c|c|c|c|}
\hline \multirow{3}{*}{ Fatores motivadores da cooperação } & \multicolumn{3}{|c|}{ Respondentes } \\
\hline & \multicolumn{2}{|c|}{ Empresas } & \multirow{2}{*}{ 1CTs $(\%)$} \\
\hline & Todas $(\%)$ & Exceto Petrobras (\%) & \\
\hline Acesso ao recurso de fomento & 52 & 64 & 78 \\
\hline Infraestrutura e capacitação do parceiro & 44 & 43 & 34 \\
\hline Complexidade técnica do projeto & 30 & 30 & 37 \\
\hline Experiência do parceiro em projetos similares & 30 & 20 & 22 \\
\hline Ter tido interação prévia com o parceiro & 30 & 27 & 18 \\
\hline Redução de riscos e incertezas do projeto & 27 & 27 & 19 \\
\hline Redução de custos & 24 & 25 & 14 \\
\hline Reputação do parceiro & 21 & 20 & 21 \\
\hline Atitude pessoal de determinados pesquisadores & 14 & 14 & 0 \\
\hline Indicação de terceiros & 0 & 0 & 5 \\
\hline Proximidade geográfica & 0 & 0 & 7 \\
\hline
\end{tabular}

Fonte: elaboração própria.

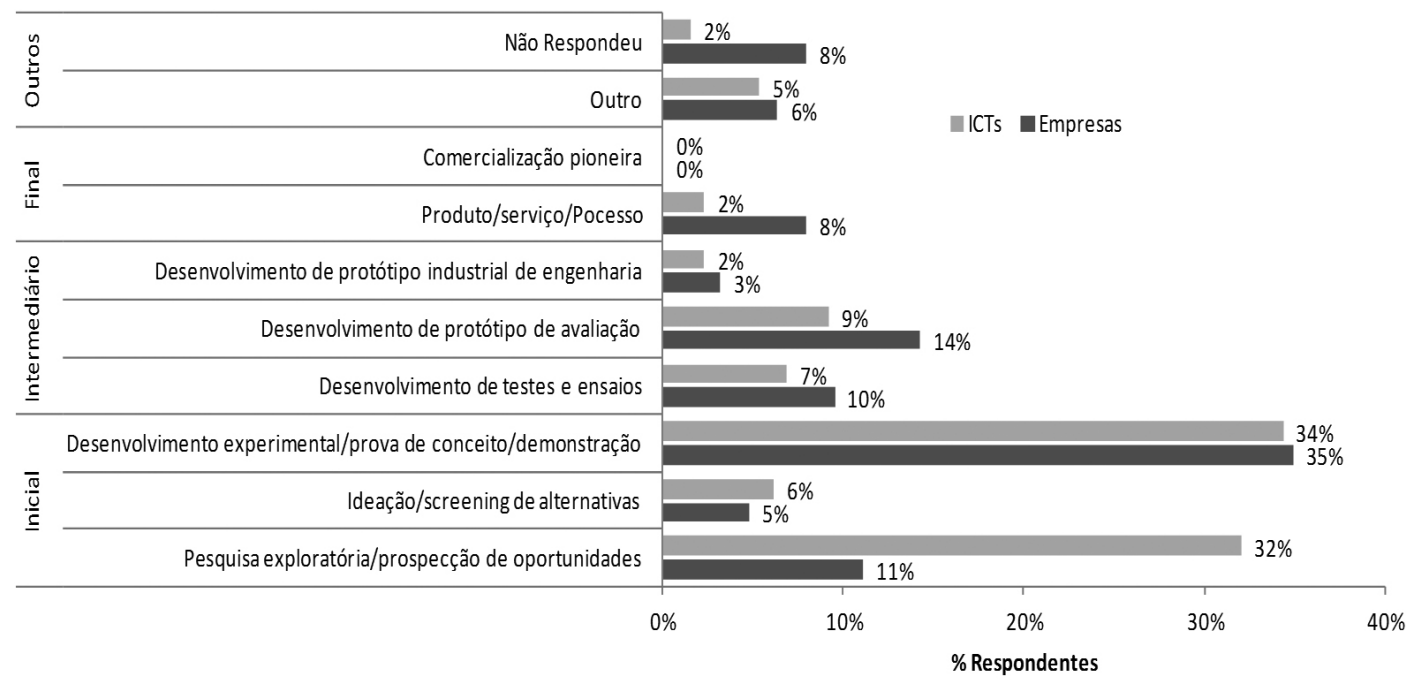

Figura 6. Estágio de desenvolvimento do projeto quando da cooperação com o parceiro. Fonte: elaboração própria. 
Tabela 8. Tratamento dos direitos de propriedade intelectual.

\begin{tabular}{lcccc}
\hline \multirow{2}{*}{ Respostas } & \multicolumn{2}{c}{ Coord. empresas } & \multicolumn{2}{c}{ Coord. ICTs } \\
\cline { 2 - 3 } \cline { 5 - 6 } & Qtd. & $\%$ & Qtd. & \% \\
\hline Houve acordo mútuo de licenciamento da tecnologia (c/ royalties) & 6 & 10 & 15 & 11 \\
A ICT deteve os direitos de Pl da inovação e licenciou a tecnologia ao parceiro & 4 & 6 & 5 & 4 \\
A ICT deteve os direitos de Pl da inovação e NÃo licenciou a tecnologia à empresa & 1 & 2 & 4 & 3 \\
Foi criada uma empresa separada, na qual ambos figuram como sócios & 0 & 0 & 0 & 0 \\
Ambos detêm os direitos de Pl, mas ainda não foi definida a estratégia de comercialização & 7 & 11 & 30 & 23 \\
Não se aplica & 35 & 56 & 57 & 44 \\
Outro & 6 & 10 & 11 & 8 \\
Não respondeu & 4 & 6 & 9 & 7 \\
Total de respondentes & 63 & 100 & 131 & 100 \\
\hline
\end{tabular}

Fonte: elaboração própria.

1CTs e $8 \%$ das empresas reportaram parcerias em casos de produtos/processos/serviços já comercializados. $\mathrm{Ou}$ seja, no âmbito desse programa, as empresas e as ICTs juntaram-se, fundamentalmente, para desenvolver projetos em estágios iniciais. Esse é um aspecto que corrobora a visão de Aghion, Dewatripont e Stein (2008), já mencionada.

\subsection{Sobre o tratamento dos direitos sobre a propriedade intelectual}

Projetos cooperativos concentrados nos estágios iniciais do processo de inovação - como no caso do Coopera - deveriam suscitar o tratamento da questão dos direitos das partes sobre a propriedade intelectual (PI) a ser gerada. Ao examinar o tratamento dado à luz dos coordenadores de projetos do Coopera que participaram da consulta, observaram-se os resultados apresentados na Tabela 8, concernente às estratégias de tratamento da propriedade intelectual.

Sintomaticamente, 56\% dos respondentes em empresas e $44 \%$ dos das ICTs indicaram que, dada a natureza de seus projetos cooperativos apresentados ao Coopera, a questão da propriedade intelectual não se aplicava - o que é consistente com uma relação entre as partes mais típica de "prestação de serviços".

Adicionalmente, praticamente $2 / 3$ dos respondentes nas empresas e nas ICTs indicaram que seus projetos cooperativos não necessitavam de acordo prévio de $\mathrm{Pl}$, ou que havia um acordo prévio que não definia o que seria feito com a Pl caso o conhecimento gerado apresentasse possibilidade de exploração comercial.

Ainda, se observa que em praticamente nenhum projeto houve criação de empresa (spin-off) para exploração da Pl gerada e somente 10\% dos respondentes das empresas e $11 \%$ das ICTs indicaram ter havido previamente acordo para licenciamento de tecnologia advinda do projeto, incluindo-se a possibilidade de exploração por meio de royalties.

\section{Considerações finais}

A cooperação universidade-empresa é uma estratégia construtiva de criação de valor, de complementaridade de recursos que podem ser orientados para a geração de conhecimento novo com valor econômico. No âmbito do programa Coopera, as evidências trazidas pela avaliação da survey dão indícios de que tal estratégia não trouxe os resultados esperados, dado que as iniciativas, ou pelo menos boa parte delas, foram mais motivadas por uma ação conservadora de acesso a recursos públicos de fomento disponíveis. Esse aspecto caracteriza parte das relações entre as empresas intervenientes e ICTs executoras no programa mais como uma relação de prestação de serviços, destas para aquelas, do que de fomento a uma ação geradora de sinergias e laços de cooperação de longo prazo. Uma consequência disso é o tratamento da propriedade intelectual, praticamente inexistente na relação entre as empresas e ICTs consultadas.

Corroborando essa visão há outro aspecto importante: a dispersão das interações. No período analisado, parte considerável das interações entre empresas e ICTs se deu uma só vez. Dentre o pequeno grupo com 5 ou mais interações ao longo desse período, a Petrobras exerce um peso significativo. A participação dessa empresa destoa do restante, cabendo uma avaliação mais detalhada do papel relativo das empresas mais atuantes no programa ao se retirar a Petrobras tanto da amostra quanto da população de empresas intervenientes. lsso também impacta a participação relativa das ICTs mais atuantes.

lgualmente, a literatura que relata experiências brasileiras, citadas neste trabalho, e os resultados obtidos nesta survey indicam que, em especial nos projetos colaborativos de natureza científica e de prazo mais longo, se observa um comprometimento superior por parte da alta administração das universidades que, em muitos casos, antecedeu os esforços governamentais desenhados para promover e estimular tal cooperação. 
Diante disso, fica evidente a necessidade de maior reflexão em relação ao que se deseja, de fato, fomentar por meio do instrumento de apoio. Isto é, desejam-se criar facilidades para as empresas que, de uma forma ou de outra, já realizam atividades de P\&D, ou se quer ampliar a base de empresas no país que tenham a inovação como estratégia de atuação? De acordo com os dados da survey, perseguir objetivos tão diversos com o mesmo instrumento pode comprometer consideravelmente os resultados esperados com a aplicação dos recursos de fomento.

Dessa forma, vista a necessidade de promover interações mais orientadas à exploração de oportunidades de mercado intensivas em conhecimento e mais longevas, a experiência de fomento público discutida neste trabalho parece sugerir que as agências de fomento não devam desperdiçar oportunidades para atuarem em regime de parceria estratégica com importantes empresas. Um passo nessa direção seria estender tais tipos de parcerias, sobretudo as de natureza finalística que já contam com algumas empresas públicas, também a grandes empresas privadas que atuam em setores de ponta ou considerados estratégicos para o país, as quais atuariam na qualidade de demandantes das soluções tecnológicas a ser desenvolvidas por ICTs e as demais empresas especializadas.

Tendo partido de um sistema de apoio à pesquisa científica relativamente recente, não se pode esperar que o estímulo à competitividade do setor produtivo por meio da sua aproximação das universidades e dos centros de pesquisa ocorra da noite para o dia no Brasil. 0 programa Coopera é uma boa prova deste esforço cujos resultados verificados até o momento, embora ainda aquém do desejado em termos de geração de inovações, é uma importante iniciativa para incorporar a inovação na cultura organizacional das empresas brasileiras.

A natureza desse estudo não permite realizar generalizações mais amplas, visto que seu objeto restringiu-se a uma avaliação longitudinal de uma única iniciativa de fomento. No entanto, pelo seu caráter de estudo exploratório, os resultados a que se chegou podem permitir que novos estudos, a partir das considerações delineadas neste trabalho, formulem hipóteses que mereçam investigações mais amplas sobre a efetividade do fomento à inovação tecnológica por meio da aproximação de empresas e universidades no Brasil.

\section{Referências}

AGHION, P.; DEWATRIPONT, M.; STEIN, J. Academic freedom, private sector focus, and the process of innovation. Rand Journal of Economics, v. 39, p. 617-635, 2008.
ANTONELLI, C. The Microeconomics of Technological Systems. Oxford: Oxford University Press, 2001.

BOTELHO, A. J. J.; ALMEIDA, M. Overcoming institutional shortcomings for academic spin-off policies in Brazil. International Journal of Technology Management \& Sustainable Development, v. 9, n. 3, p. 175-193, 2010. http://dx.doi.org/10.1386/tmsd.9.3.175_1

BOTELHO, A. B.; PIMENTA-BUENO, J. A. Financiando as Relações entre a Universidade e a Indústria na América Latina: um apoio às universidades ou estímulo à inovação? In: SCHWARTZMAN, S. (Ed.). Universidades e Desenvolvimento na América Latina: experiências exitosas de centros de pesquisas. Rio de Janeiro: Centro Edelstein de Pesquisas Sociais, 2009.

BRITTO, J. N. P. et al. Produtividade, Competitividade e Inovação na Indústria Brasileira. In: KUPFER, D.; LAPLANE, M. F.; HIRATUKA, C. (Org.). Projeto PIB vol. 4 - Perspectivas do Investimento no Brasil: Temas Transversais. Rio de Janeiro: Synergia, 2010. p. 297-341.

CARLSSON, B. et al. The Knowledge Filter, Entrepreneurship, and Economic Growth. Jena Economic Research Papers, 2007. v. 57.

CASSIOLATO, J. E.; LASTRES, H. M. M. Sistemas de inovação e desenvolvimento: as implicações de política. São Paulo em Perspectiva, v. 19, p. 34-45, 2005. http://dx.doi. org/10.1590/S0102-88392005000100003

COELHO, R. B. M. Pesquisa e Pós-graduação: Perspectivas das agências de fomento para 2008-2011. In: REUNIÃO DO FÓRUM DE PRÓ-REITORES DE PESQUISA DA REGIÃO SUDESTE, 2007, Ouro Preto. Anais... Ouro Preto, 2007.

CRUZ, C. H. B.; MELLO, L. Boosting Innovation Performance in Brazil. OECD Economics Department, 2006. Working Papers, n. 532.

DEWATRIPONT, M.; STEIN, J. Academic Freedom, privatesector focus, and the process of innovation. RAND Journal of Economics, v. 39, p 617-635, 2008. http:// dx.doi.org/10.1111/j.1756-2171.2008.00031.x

ETZKOWITZ, H. et al. The Future of the University and the University of The Future: evolution of ivory tower to entrepreneurial paradigm. Research Policy, v. 29, n. 2, p. 313-330, 2000. http://dx.doi.org/10.1016/S00487333(99)00069-4

FERNANDES, L. M. R. A FINEP e a Inovação nas Empresas. ln: FÓRUM NACIONAL, 20., 2008, Rio de Janeiro. Anais... FINEP, 2008.

FINANCIADORA DE ESTUDOS E PROJETOS - FINEP. Brasil Inovador. Rio de Janeiro: FINEP, 2008. Disponivel em www.finep.gov.br/dcom/brasilinovador.pdf.

FINANCIADORA DE ESTUDOS E PROJETOS - FINEP. Relatório de Gestão 2003-2006. Rio de Janeiro: FINEP, 2006.

FINANCIADORA DE ESTUDOS E PROJETOS - FINEP. Relatório de Gestão 2004. Rio de Janeiro: FINEP, 2004.

GIULIANI, E. et al. Why do Researchers Collaborate with Industry? An analysis of the wine sector in Chile, South Africa and Italy. CREl, 2009. CREl Working Paper - Università di Roma Tre n.1. Disponível em: <http://host.uniroma3.it/centri/crei/pubblicazioni. html>. Acesso em: 12 maio 2012.

LA ROVERE, R. L.; RODRIGUES, R. F. Outsourcing and Diffusion of Knowledge in ICT Clusters: A Case Study. In: PYKA, A.; FONSECA, M. G. D. Catching up, spillovers and Innovation Networks in a Schumpeterian 
Perspective. Berlin: Springer-Verlag, 2011. http://dx.doi. org/10.1007/978-3-642-15886-5_13

MATEl, A. P. et al. Avaliação da qualidade demandada e diretrizes de melhoria no processo de interação Universidade-Empresa. Produção, v. 22, n. 1, p. 27-42, 2012. http://dx.doi.org/10.1590/S010365132012005000002

MELO, L. M. Financiamento a Inovação no Brasil: análise da aplicação dos recursos do Fundo Nacional de Desenvolvimento Científico e Tecnológico (FNDCT) e da Financiadora de Estudos e Projetos (FINEP) de 1967 a 2006. Revista Brasileira de Inovação, v. 8, n. 1, p. 87120, 2009.

MIGUEL, P. A. C. (Org.). Metodologia de Pesquisa em Engenharia de Produção e Gestão de Operações. Rio de Janeiro: Campus-Elsevier, 2012.

MONTOBBIO, F.; STERZl, V. Inventing Together: Exploring the Nature of International Knowledge Spillovers in Latin America. In: PYKA, A.; FONSECA, M. G. D. Catching up, spillovers and Innovation Networks in a Schumpeterian Perspective. Berlin: Springer-Verlag, 2011. http://dx.doi. org/10.1007/978-3-642-15886-5_5

MORELI, E. C. As contribuições do Fundo Verde-Amarelo para as Empresas Usuárias do Fundo. 2009. Dissertação (Mestrado em Engenharia de Produção)-Universidade de São Paulo, São Paulo, 2009.

NOGUEIRA, M. 0.; KUBOTA, L. C.; MILANI, D. N. CT-INFO: uma visão a fundo. Revista Brasileira de Inovação, v. 10, n. 2, 2011.
PARANHOS, J.; HASENCLEVER, L. The Relevance of IndustryUniversity Relationship for the Brazilian Pharmaceutical System of Innovation. In: PYKA, A.; FONSECA, M. G. D. Catching up, spillovers and Innovation Networks in a Schumpeterian Perspective. Berlin: SpringerVerlag, 2011. http://dx.doi.org/10.1007/978-3-64215886-5_12

SAPIR, A. et al. An agenda for a growing Europe: making the EU economic system deliver. Economic Commission, Brussels, 2003.

SCHWARTZMAN, S.; BOTELHO, A.; ALVES, A. Brazil. In: SCHWARTZMAN, S. (Ed.). Universidades e Desenvolvimento na América Latina: experiências exitosas de centros de pesquisas. Rio de Janeiro: Centro Edelstein de Pesquisas Sociais, 2009.

TASSEY, G. The Economics of R\&D Policy. Quorum Books: Wespport, 1997.

VERMULUM, R.; HOLLANDA, S. Os novos instrumentos de apoio à inovação: uma avaliação inicial. Brasília: Centro de Gestão e Estudos Estratégicos, Associação Nacional de Pesquisa e Desenvolvimento, 2008.

VILlA, A.; ANTONELll, D. (Eds.). A Roadmap to the Development of European SMEs Networks: towards collaborative innovation. London: Springer-Verlag, 2009. http://dx.doi.org/10.1007/978-1-84800-342-2

WEBSTER, A. International Evaluation of Academic-Industry Relations: Context and Analysis. Science and Public Policy, v. 21, p. 72-78, Apr 1994.

\begin{abstract}
The paper analyses the financing of the efforts of firms to innovate through partnerships with universities and research centers, which constitute an important means of fostering innovation. In the Brazilian case, the combination of the resources of federal and state agencies and the universities' infrastructure, consolidated in recent decades, acts as a link to enhance this effort. This study examines university-industry interaction in pursuit of innovation using the results of a survey carried out among universities and firms that participated in a national program called COOPERA between 2002 and 2007. This study explores several aspects of the nature of the relationship created by the COOPERA innovation promotion instrument. While progress has been made, the analysis results suggest that the program has not yet succeeded in establishing the quality and frequency of relationships that depend on the continued support of innovation efforts by Brazilian firms.
\end{abstract}

\title{
An exploratory assessment of public financing of university-industry cooperation in Brazil
}

\section{Keywords}

Science and technology institutions. Science and technology policy. University-industry cooperation. 